\title{
Introducción: Ensanchando el lente crítico para el centenario de Jaime Saenz (1921-1986)
}

\author{
Tara Daly y Raquel Alfaro \\ Marquette University \\ University of Rochester
}

Como describe el comentario de la contratapa, la portada de este volumen especial en honor al centenario del reconocido poeta y escritor Jaime Saenz, es una foto que ofrece la sugerencia de la puerta de una bodega sin ser realmente aquella. Tras esta puerta, no obstante, se esconde un misterio para el transeúnte común y esto es lo que aproxima e incluso asimila la puerta fotografiada con la idea de bodega acuñada por Jaime Saenz. Escogimos esta imagen como portada porque creemos que la obra saenceana sigue escondiendo misterios aún por descubrir, como la callejuelita que se insinúa al fondo de la foto, extendiendo una invitación - como el grupo de artículos críticos contenidos aquí- para explorar las profundidades de la propuesta literaria de Saenz. Allí la invitación abierta que nos incita a seguir ese sendero recóndito, más allá de la portada de la bodega-no-tan-bodega, para preguntarnos qué se halla en el inicio de esa curvatura. Esta imagen es una apertura que nos sitúa en La Paz de 1979 y, a la vez, en La Paz de hoy en día, que sigue siendo tan dinámica y sorprendente como aquella otra. $\mathrm{Y}$ un recordatorio de que a pesar del paso del tiempo (cien años desde su nacimiento), Saenz sigue estimulando interés crítico y ganando reconocimiento como uno de los poetas y escritores latinoamericanos más audaces y originales del siglo XX. 
Nosotras dos, probablemente como muchos de nuestros lectores, recordamos muy bien el día que abordamos por primera vez uno de los trabajos literarios de Saenz y supimos así de su existencia. Yo, Tara, estaba de viaje en Guatemala, irónicamente, visitando una comunidad remota de la región de Petén. Después de regresar a la capital, sentí una extraña soledad y a la vez una alienación de mí misma, algo que ocurre con uno de vez en cuando, o quizás frecuentemente, como parte de nuestra condición humana. En estos momentos, recurría a la poesía para obtener la compañía que extrañaba, para sentirme menos sola en un ambiente en que parecía no encajaba y difícilmente entendía. En un hostal chiquito, con mi laptop primitivo, empecé a buscar poetas bolivianos, porque la semana entrante iba a ir por primera vez a Bolivia. Tenía unos veintidos años entonces. Encontré el poema titulado "La Noche" y una pregunta postulada en este texto llamó mi atención: “¿Y qué decir de la honda soledad, habitando el espacio de tu cuerpo?". Me sentí de inmediato interpelada por Saenz como si yo fuera la única "tú" a quien se dirigía el poema $y$, en aquel instante, deseé nadar (y hacía en verdad mucho calor) en la resonante poesía saenceana. Por suerte, poco después, me topé con el sitio de Leonardo García Pabón, que ha mantenido por años, dedicado a la vida y obra de Jaime Saenz. Por fin, comencé a sentirme acompañada en Guatemala, después en Bolivia, al pasar por puentes extraños y mojados en rinconcitos de La Paz, más tarde al trasnocharme en los Estados Unidos. Desde entonces siempre me sentí una visitante bienvenida y deseosa de ser habitante de la ciudad mágica de Saenz. No saber como descifrar un texto, una ciudad, un espacio, es parte de la belleza y la pena que nos ofrecen éstos que nos dan la vida. Como tantos aficionados de Saenz, me convertí en una más de aquellos que asumen tener alguna conexión cósmica con el autor y obra que estudian: fenómeno que Leonardo García Pabón ha nombrado, apropiadamente, "el efecto Saenz" ("The Saenz Effect. An Afterword by Leonardo García Pabón”. En Jaime Saenz, Immanent Visitor: Selected Poems of Jaime Saenz. University of California Press, 2002. 141-145).

A esta perspectiva mía, proveniente de una extranjera, se suma como un complemento, la de Raquel: boliviana de familia cochabambina educada en La Paz, pero que ha residido por décadas en los Estados Unidos. Yo, Raquel, conocí la obra de Saenz como estudiante de literatura, en La Paz, Bolivia. La adoración por la poesía y prosa sanceanas allí estaba en el aire. Profesores y estudiantes no dejaban de nombrarlo, a pesar de que curiosamente no figuraba en las listas de lecturas obligatorias de los diferentes cursos de literatura y poesía bolivianas. A diferencia de Tara, el texto de Saenz que me cautivó fue uno 
narrativo, Imágenes paceñas, pues este texto me hizo redescubrir mi mundo (La Paz) al convertir ese entorno, que asumía hasta ese momento absolutamente familiar, en una realidad extraña. Una experiencia que transformó no sólo mi mirada hacia fuera sino también hacia dentro de mí, y me obligó a repensarme junto con mi entorno.

Tras zambullirme en la poesía y narrativa de Saenz, quedé cautivada por esa otredad radical, una constante en esta obra que produce una sensación de profunda inquietud en la medida en que el rostro de ese otro (sugerido) no termina de dibujarse. Por eso uno nunca llega a asirlo a pesar de estar tan cerca. Algunos años después, tomé un seminario sobre la obra de Saenz con Elizabeth Monasterios. En este seminario se propuso la asociación crítica de esa inquietante y al parecer inasible otredad con expresiones y prácticas culturales concretas, ligadas y provenientes del mundo aymara. Se allanó un camino que yo difícilmente intentaba abrir. Releí entonces la obra de Saenz a través de este nuevo cristal crítico, lo que me permitió descubrir otros y sugerentes sentidos en la misma. Mi tesis de licenciatura, centrada en Felipe Delgado, fue la materialización del derrotero al que me embarqué en aquel momento. Pero la obra de Saenz también indujo un cambio interno en mí. Junto con él, me saqué el cuerpo y comencé a buscar en mí y en lo que leo, esa otredad familiar, una que nos habita como quienes somos: hijas/os de un universo (paceño/boliviano) enmarañado con lógicas culturales indígenas.

Sin nuestras experiencias complementarias por asimétricas, no hubiéramos podido elaborar este volumen. Tampoco hubiéramos podido poner en movimiento este proyecto sin nuestra experiencia transitando los diversos extremos de la urbe paceña, sin haber trepado y resbalado por sus singulares calles empinadas de piedra lustrosa por el uso y abuso, sin habernos maravillado juntas por su impresionante topografía. Es precisamente en un departamentito en uno de los barrios paceños tradicionales, Sopocachi, que confabulamos juntas este proyecto mirando desde la ventana la ciudad de Saenz, la ciudad nuestra.

Sumándonos a un esfuerzo conjunto por rendir homenaje a un gran poeta y escritor boliviano, excéntrico y contradictorio también, este volumen persigue sugerir nuevas vetas críticas y generar otras conversaciones a propósito de la obra de Saenz. Reconociendo los alcances y limitaciones de este nuestro proyecto, creemos importante la renovada mirada ofrecida por los artículos contenidos en estas páginas, y sabemos que estas voces críticas van a unirse a aquellas otras nacidas en diferentes lechos críticos. Es necesario además señalar que la convocatoria extendida que se ha 
materializado en este volumen fue una llamada abierta e internacional y acogió las contribuciones de académicos de varios rangos y posiciones críticas, investigadores independientes y estudiantes graduados. Hicimos esto con el fin de propiciar un espacio en donde se combinaran distintas entradas, aquellas de estudiosos de la obra saenceana con esos nuevos acercamientos críticos de quienes fueron, de manera reciente, capturados por este tejido literario. Esperamos haber conseguido compilar una variedad de textos críticos que alienten a nuevas generaciones de estudiosos a explorar la poesía y la prosa, la filosofía y el misticismo, el teatro y los dibujos, la palabra y el silencio de Saenz.

La diversidad de contribuciones críticas que giran tanto en torno a la obra poética como a la prosa de Saenz, ofrecidas aquí, producen resonancias y trazan ejes de los cuales queremos dar cuenta en esta introducción. Usando marcos teóricos variados y elaborando lecturas minuciosas de distintos textos, las mismas coinciden en observar que la obra saenceana explora lógicas culturales alternativas a las que determinan al sujeto racional anclado en una modernidad uniforme, lo que abre rutas de indagación y permite imaginar y proyectar formaciones sociales distintas e inesperadas en tanto pueden devenir puntos de resistencia a políticas globalizadoras que amenazan con borrar todo lo diferente. Siguiendo la línea de lectura de Javier Sanjinés, quien señala la lógica obversa que caracteriza la aproximación de Saenz al desarrollo de sus narrativas, el mundo literario saenceano es capaz de capturar las tensiones de una urbe y de una sociedad donde una topografía extrema no puede desligarse. Además, es cómplice de una larga historia de resistencia al colonialismo, tanto externo como interno. Esto se expresa en el hecho de que, a pesar de los cambios asociados con la industrialización y el capitalismo con su correlato de inserción de avances tecnológicos, la obra saenceana devela otros modos de vida en La Paz que retan la uniformidad. Saenz insiste en reconocer formas de pensamiento provenientes de otras culturas; en este caso, la aymara, que ha posibilitado la gestación de una modernidad particular e inusual. Esto porque es una modernidad que, sin sustraerse de los flujos económicos capitalistas, consigue desviarse de modelos sociales y proyectos políticos derivados de este hacer económico para crear formaciones sociales alternativas e impulsar la reinvención política de Bolivia.

Otra veta explorada es la sugerente conexión —curiosamente semejante al duende de Federico García Lorca - del mundo material con uno metafísico y atemporal hecha por la propuesta saenceana. Es claro que el camino místico, creativo e incluso mágico abierto por Saenz aún no ha sido del todo recorrido. 
De allí que se ensayen nuevas miradas sobre poemas como La Noche y se multipliquen las lecturas de la enigmática prosa de Felipe Delgado. Las obras literarias de Saenz nos regalan una comprensión concreta, por medio de nuestros cuerpos y a través de nuestros sentidos, de la ciudad de La Paz y, a la vez, de esa Bolivia profunda y escondida a plena luz del día que se manifestó cuando un líder político de origen indígena, Evo Morales, devino presidente en el 2005. Pero asimismo éstas nos conectan con lo efímero de la vida, de su mundo, de nuestro mundo, con aquellas experiencias fugaces como la presencia del Illimani (más allá de su ser montaña) o la otra noche, esa "que se mira". Obligados por la predilección saenceana de pensar siempre desde la otra orilla (la muerte, lo efímero, la otredad cultural), nosotros lectores, alejados de las seguridades ofrecidas por lo familiar y lo permanente, recorremos las callejuelas paceñas. Ellas son siempre, aunque inadvertidamente, marcadas por la sombra de las montañas que rodean esta urbe y que la determinan y la contienen, con su verticalidad casi infinita. Asimismo, y como un efecto paralelo, nos adentramos en aspectos universales de la condición humana: la fascinación y el rechazo que residen en el corazón de la vida y la muerte.

Se entrelaza con lo anterior, la atención puesta al singular telurismo saenceano. Tenemos así una lectura revisionista de la asimilación y digestión de las corrientes telúricas tradicionales de Saenz y su materialización en su obra, por una parte. Por otra, se ofrece una novedosa entrada a la influencia del suelo en los que lo andan, lo habitan, a través del pensamiento postantropocéntrico. No es casual la persistencia de las planicies altiplánicas como espacio geográfico que se infiltra, altera y determina la realidad tanto de la voz poética como la de los personajes de la prosa saenceana. Y cobra una dimensión distinta cuando se piensa este escenario altiplánico imbricado inexorablemente a la cultura aymara, al punto de ser capaz de reproducir e infectar con sus sentidos y prácticas a la urbe paceña y a sus moradores, creando un estar(se) andino/aymara que afecta todos los aspectos de la vida urbana.

Abordando una esfera poco explorada en la obra de Saenz por la crítica, la temática de la sexualidad se rastrea en distintos textos narrativos (Felipe Delgado, Los papeles de Narciso Lima-Achá e Imágenes paceñas). En su conjunto, los autores exploran la curiosa naturaleza de relaciones amorosas que problematizan la heteronormatividad. También, se estudia esa temporalidad otra (una queer) que cruza la urbe paceña opuesta al binarismo de género y que, por lo mismo, desestructura los fundamentos del orden dominante 
mientras postula un eje alternativo al tiempo de la reproducción material capitalista. De esta manera, la autoidentificación de Saenz como bisexual (un elemento extradiegético) es creativamente indagada en su obra por esta vena crítica, una que esperamos este volumen impulse.

Es necesario apuntar que este volumen no hubiera sido posible sin los trabajos críticos de previas generaciones a la nuestra que reconocieron la brillantez de Saenz y disfrutaron de su amistad. Luis H. Antezana y Blanca Wietüchter fueron dos de los críticos más tempranos que enfatizaron los elementos místicos del mundo imaginario-poético tejido por Saenz, y que por haber compartido el espacio urbano con él, en los Talleres Krupp o en otros eventos de la ciudad, apreciaron y entendieron los códigos de la ciudad que Saenz intuitivamente captó en su poesía y en su prosa. Wietüchter, aunque no fue estudiante directa de Saenz, le consideró un maestro. Y es ella que escribió el primer estudio sobre el universo poético de este escritor que fue publicado como ensayo de apéndice a Obra poética, en 1975. En este texto, esta voz crítica se acerca a la producción literaria de Saenz con lecturas minuciosas y un entendimiento profundo del entorno local (La Paz). En este sentido, estos críticos tuvieron la dicha de este tan especial "convivir artístico" en el entorno paceño y boliviano. Leonardo García Pabón también compartió espacios íntimos de la ciudad con Saenz y vincula la mirada poética de La Paz de este autor con reflexiones inscritas dentro del marco nacional de la literatura y las letras bolivianas. Con su sitio web dedicado a Saenz y su compromiso, por décadas, de difundir las obras de este escritor y trabajos críticos referidos a éstas tanto en Bolivia como afuera, García Pabón ha contribuido al reconocimiento de Saenz como figura literaria nacional e internacional. Este esfuerzo ha puesto a Bolivia en el mapa de la poesía latinoamericana contemporánea, aún con sus idiosincrasias. Se suma a los mencionados, Javier Sanjinés C. con sus estudios profundos de la producción cultural boliviana. Quizás uno se sus trabajos más notable está en Mestizaje Upside-Down: Aesthetic Politics in Modern Bolivia. Sanjinés nos propone entender la obra saenceana como parte de una larga tradición de letras en Bolivia y destaca los modos en que Saenz ha cambiado la imaginación colectiva nacional al incorporar "personajes" marginales dentro de la conciencia nacional literaria. Además, Sanjinés ha situado a Saenz en el campo de la literatura comparada y transatlántica, ejemplifiado en el artículo suyo incluido en este volumen.

Sumándose a la crítica que surgió a finales de los 70 y 80, en las últimas décadas, y en respuesta a la interdisciplinaridad, globalización y emergencia 
de teorías vinculadas a la descolonización intelectual, surgen trabajos como el de Elizabeth Monasterios, que ha interrogado por primera vez la incidencia de sistemas de pensamiento indígenas en la producción literaria de Saenz. Esta intervención implica la consideración del área andina no como una serie de naciones autónomas sino una contigüidad geográfica y cultural. El artículo de Monasterios en este volumen continúa enriqueciendo esta vena crítica. En paralelo con estas aproximaciones ligadas a lógicas de pensamiento indígenas/andinas, se tiene las muestras del interés crítico despertado por la obra sanceana fuera de Bolivia y de estudios literarios y críticos latinoamericanos. Forrest Gander y Kent Johnson, por ejemplo, publicaron una traducción al inglés de una selección de poemas de Saenz en Immanent Visitor, una edición bilingüe (University of California Press, 2002). Años después publicaron La Noche/The night (Princeton University Press, 2018), el último poema de Saenz, escrito antes de su muerte. Es preciso señalar que la obra de Saenz ha sido también traducida al alemán e italiano, aunque todavía no al francés. Con el centenario de su nacimiento, sin embargo, se espera la renovación del interés en su obra no solamente dentro de Bolivia sino también en las redes globales de literatura. En la prensa diaria boliviana y en las Ferias del Libro se ve la atención que Saenz está recibiendo de nuevo, contribuyendo a su continuación como ícono poético. El estudio crítico de la obra poética saenceana coordinado por Mónica Velásquez: La crítica y el poeta. Jaime Saenz, publicado por Plural Editores en 2011, es un ejemplo de lo anotado. Asimismo, se tiene la compilación del trabajo crítico de Luis Antezana recientemente publicado por la editorial Mariposa Mundial y Plural editores, en conmemoración del aniversario de Saenz. Pero la atención a la obra saenceana no se limita al campo literario. La compañía de teatro de David Mondacca ha llevado al ámbito teatral varios textos de Saenz. En honor a este poeta y escritor, esta compañía ha puesto videos de algunas de estas piezas teatrales a disposición del público por medio de redes sociales y YouTube.

\section{Resúmenes de capítulos}

En el primer capítulo, Elizabeth Monasterios retorna una vez más a Saenz y expande sus diversas y enriquecedoras lecturas sobre la obra de este poeta y escritor, entre las que destaca su libro titulado Dilemas de la poesía de fin de siglo: José Emilio Pacheco y Jaime Saenz (Plural Editores, 2001). Monasterios, en el libro indicado, tiende un tramado teórico que le permite postular las conexiones que la intuición poética saenceana establece con saberes, prácticas y sentidos vinculados a la cultura aymara. Siguiendo esta línea de lectura, pero 
expandiéndola, en el artículo incluido en este volumen, ella discute la cuestión del "estar" en la poética de Saenz como una elaboración artísticoepistemológica que se inscribe en una tradición poética, crítica y filosófica nacida en lechos intelectuales plebeyos y que por lo mismo es alternativa a reflexiones latinoamericanas canónicas. En diálogo con su investigación y estudio del escritor peruano Gamaliel Churata (1897-1967) y del filósofo argentino Roberto Kusch (1922-1979) -quienes, es necesario precisar, vivieron en Bolivia ya sea por razones políticas o académicas - y poniendo a dialogar las propuestas de éstos con la de Saenz, destaca las formas en que los tres autores articulan una filosofía del estar distante e incluso opuesta a la del "ser en el mundo" de Heidegger. Subraya la importancia del estar (la ubicación física) en el proceso de construcción y definición ontológicas del individuo al interior de las lógicas culturales andinas. La intervención teórica de Monasterios ilumina así la pertinencia de considerar cuestiones filosóficas desde perspectivas no uniformemente occidentales. Como se verá más adelante, esta propuesta dialoga con las lecturas críticas de Imágenes paceñas ofrecidas por los artículos de Irina Feldman, Christian Elguera y el nuestro, donde también se exploran los nexos entre la obra de Saenz y lógicas culturales andinas a partir del espacio.

La lectura crítica de la novela Felipe Delgado que hace Javier Sanjinés C. es la segunda entrada en este volumen. Aquí Sanjinés, al igual que Monasterios, elabora una propuesta que va a complementarse con sus reflexiones sobre obras literarias bolivianas y las expresiones culturales de la región andina. En este artículo, el autor ofrece un análisis iluminador de la novela indicada, prestando atención a la forma en que Felipe, el personaje principal, encarnando una lógica alternativa o, en palabras del propio autor: obversa, se distancia de la figura del personaje peripatético típico de la novela tradicional. En la primera parte de su ensayo, Sanjinés nos hace recuerdo de Robinson Crusoe, el náufrago de la novela de Daniel Defoe. En este personaje, el autor identifica una "transfiguración moderna del mito del homo selvaticus" necesaria para establecer los fundamentos para la aparición del homo economicus de la literatura del siglo XIX y principios de siglo XX. Este Robinson, funcional al proyecto liberal en tanto puede superar su estado de naturaleza no solo en la práctica económica sino en el plano estético también, sirve a Sanjinés como un prototipo en relación con el cual se pueden leer personajes novelescos atípicos que funcionan como su reverso. Estos Robinsones disfuncionales, torceduras del Robinson original, se desarrollarían en novelas que giran en torno al "encholamiento", particularmente las obras de Carlos 
Medinaceli. Distanciándose de la funcionalidad del Robinson de Defoe y de la disfuncionalidad de héroes novelescos de historias donde se representa el mundo cholo, emerge Felipe Delgado, quien no es ni funcional ni disfuncional al proyecto de la modernidad y, adhiriéndose a una lógica obversa, deviene una parodia de este proyecto. Así, este personaje resulta un "grotesco jubiloso": una celebración de un tipo de comportamiento que va en contra del asumido por el homo economicus.

Marcando un interesante contrapunto al artículo de Sanjinés, se tiene la propuesta de Camilo Gil Ostria, un estudiante de literatura boliviana de la Universidad Mayor San Andrés (UMSA). Mientras, como vimos, Sanjinés lee críticamente el derrotero trazado por Felipe Delgado en la totalidad de la novela, Gil Ostria más bien se concentra en un pasaje/capítulo específico. Intenta el autor iluminar un aspecto de Felipe muy poco estudiado: su posición transexual, para sugerir después la posibilidad de repensar a este personaje y su trayectoria bajo esta nueva luz. De manera creativa y estableciendo un sugerente contrapunteo con otra novela de Saenz, Los papeles de Narciso Lima Achá, el autor analiza la forma en que Felipe, desafiando el concepto tradicional de binarismo genérico -aunque sea momentáneamenteencarna comportamientos y adopta posiciones transexuales. De este modo, señala Gil Ostria, esta novela mostraría cómo la transexualidad, entendida ordinariamente como un cambio de sexo (de hombre a mujer, de mujer a hombre), en el contexto de la novela resulta un complejo proceso que más bien revela la arbitrariedad de las nociones binarias de género/sexo. Como consecuencia, a juicio del autor, la alteridad en Felipe Delgado se aleja del concepto de lo "neutro" barthesiano, pero, curiosamente, esta posición altérica que se alcanza gracias al camino amoroso, no llega a ser sostenible. Felipe, tras experimentar un proceso de transexualización, vuelve a encajar su comportamiento y reenfocar su mirada en un mundo regido por el binarismo genérico. Y toda esta reflexión crítica viene originalmente acompañada por la obra pictórica de Magritte que, para Gil Ostria, muestra visualmente lo que Saenz revela escrituralmente: el acto de revelar y esconder a la vez, bañando, al final, de ambigüedad e irresolución lo que propone la obra.

A estos tres primeros capítulos, el primero que establece un marco filosófico para leer la poesía de Saenz y los siguientes dos enfocados en Felipe Delgado, continúan dos que giran en torno a la producción poética de Saenz. En el cuarto capítulo, Joseph Mulligan presenta una lectura del poemario Muerte por el tacto (1957), demostrando un conocimiento profundo del telurismo literario de la época dentro de un marco transatlántico. En la misma, 
plantea pensar al poeta como médium que rechaza las convenciones de la razón instrumental y abraza un genius loci o el espíritu de la tierra. Sería ese el amor exagerado por un orden invertido (desorden) de la voz poética que lo haría inclinarse a cuestionar la razón instrumental y percibir el peligro que la misma conlleva en tanto rige sobre asuntos espirituales. Esta línea de reflexión lleva a Mulligan a argumentar que, en contra de lecturas críticas tradicionales que ubican a la voz poética saenceana en un plano metafísico o distante de los haceres de la sociedad, es posible ubicar esta voz poética en la comunidad, como parte y expresión de la misma. Así, se sitúa el trabajo literario de Saenz en el espectro de lo literario oracular dado que la voz poética deviene una suerte de custodio cultural que media entre la inmediatez pre-reflexiva y el sujeto no reflexivo de la cultura de masas.

En el quinto capítulo encontramos la sugerente lectura del poema La Noche (1984) de Víctor Vimos. El autor analiza y reconstruye el proceso de transformación de la voz poética en La Noche, resaltando cómo esta última se desplaza desde un estado de automatización hacia uno de iluminación donde se atestigua el desbordamiento de la palabra (palabra que excede a la palabra). La paradoja derivada no es posible - a juicio del autor - sin el componente místico. Dentro de este marco místico, se revela el hacer de un lenguaje poético que es dispuesto a manera de una red que tiene como objetivo capturar toda la realidad signada por la enunciación. Esta red está empeñada en contener, en el terreno de la significación, cualquier acto humano. Como resultado de estas transformaciones poéticas de corte místico, se genera un lenguaje poético que, distanciado de su funcionalidad significativa, cuestiona abiertamente las versiones racionales/occidentales de la realidad.

Retornando a la producción narrativa saenceana pero inserto dentro de la esfera de los análisis comparativos, encontramos el capítulo de Christian Elguera. En el mismo se inicia un intenso diálogo entre una obra de Jaime Saenz (Imágenes paceñas) y una de José María Arguedas (Tupac Amaru Kamaq Taytanchisman), anclado en el rol de la naturaleza -manifestada en serpientes, ríos, montañas, etc. - y su determinante impacto en la producción y organización, imaginaria y material, del espacio urbano de La Paz y Lima respectivamente. Inscribiendo su propuesta dentro de la vena crítica fundada en el cuestionamiento del antropocentrismo, Elguera encuentra en los trabajos literarios estudiados formas alternativas (e incluso opuestas a las apoyadas en parámetros antropocéntricos) de entender el espacio nacidas de ontologías indígenas articuladas en contextos urbanos. Esta interpretación gira en torno a dos ejes comunes a las obras saenceana y arguedeana: un 
más allá del indigenismo y el concepto de la interconectividad ontológica que desafía nociones que distancian y enfrentan naturaleza y cultura. A lo largo de su reflexión, Elguera marca tanto las semejanzas como las diferencias entre Saenz y Arguedas con el propósito de desenterrar una modernidad idiosincrática que operaría según lógicas culturales altéricas (en este caso, andinas) y de poner su propia lectura en diálogo con un debate teórico actual, el post-antropocentrismo, que está hoy en día incitando el repensar los fundamentos de las humanidades.

Explorando un trabajo literario narrativo particular de Saenz, Imágenes paceñas, se tiene tres capítulos que ofrecen diferentes entradas críticas. La contribución de Irina Feldman, poniendo a dialogar la obra saenceana con la de Víctor Hugo Viscarra destaca, en un marco comparativo, las lógicas temporales de la ciudad de La Paz reveladas por los trabajos literarios de estos dos reconocidos escritores paceños. Para Feldman, la narrativa saenceana revela en la "ciudad oculta" un ritmo temporal predicado en una materialidad transcendental que proviene de la naturaleza andina. Por su parte, Viscarra más bien vería en esa misma urbe un movimiento que, lejos de impulsar la trascendencia, incitaría a sumergirse en ella, a experimentar inmanentemente. Yuxtapone así al morador de los basurales de Saenz, concebido como un individuo que tiene "acceso privilegiado al conocimiento", con la representación de esta misma figura paceña a través de la mirada de Viscarra, que enfatiza no el lado romántico de esta vida marginal y precaria sino las condiciones infrahumanas de existencia que obligan a sobrevivir mediante acciones no siempre dignificadas. Esta yuxtaposición, no obstante, busca mostrar cómo los trabajos literarios de Saenz y Viscarra son complementarios. Mientras Viscarra subraya la destitución material sufrida por ciertos habitantes de la urbe paceña que los confrontan con la finitud, Saenz destacaría el aura que los rodea y que les permite conectarse con saberes escondidos, viabilizando su trascendencia.

En el siguiente capítulo, nosotras nos concentramos en la idea de la magia articulada por Saenz en Imágenes paceñas. Organizamos nuestra discusión sobre magia en tres secciones. En la primera, discutimos la magia en relación con La Paz como sitio urbano mágico por ser andino. En la segunda, hablamos sobre la magia de habitar la ciudad, contrastando el "habitar" con el "construir" de Heidegger. En la tercera parte, la magia es pensada en el plano extradiegético y enlazada con el montaje para interpretar la no casual tensión entre texto e imagen producida en Imágenes paceñas. Una vez reconstruido el mapa mágico trazado por el trabajo literario de Saenz, terminamos el capítulo 
con la sugerencia de que La Paz todavía hoy, en siglo XXI, conserva su magia en tanto produce formas de habitar el mundo únicas y opuestas (aunque no al margen) del ritmo capitalista; y que las manifestaciones del espíritu mágico paceño identificadas por Saenz, podrían muy bien ser encontradas en la actual ciudad de El Alto.

A manera de apéndice a nuestro capítulo, incluimos una entrevista con Javier Molina, fotógrafo de Imágenes paceñas, quien explica su colaboración con Saenz generando un archivo visual de la ciudad que después fue usado en Imágenes paceñas. En la conversación, Molina apunta que las fotografías de La Paz constituyen un archivo histórico visual que captura una La Paz "netamente andina" que -como Saenz lo señala en su época- estaba condenada a desaparecer a medida que su modernización se hacía inminente, y que hoy en día habría perdido su aura andina. Sin embargo, haciendo eco de una sugerencia anotada en nuestro artículo, indica este fotógrafo que algunos aspectos y sujetos celebrados por Saenz en la urbe paceña de los 70 se han trasladado a El Alto del siglo XXI. Ahora bien, el registro visual de la urbe paceña localizado al interior del trabajo fotográfico de Molina, el cual hoy en día está abocado a lo digital y experimental, curiosamente revela el deseo de este fotógrafo de capturar lo fantástico que producen paisajes y perfiles como hilo conductor a su corpus. Un ejemplo de lo anotado es la fotografía que Molina generosamente compartió con nosotras y que es la portada de la versión impresa de este volumen, pues en la misma se captura el espíritu de la bodega sin que este lugar realmente lo sea. La sugerencia es lo suficientemente fuerte para producir el efecto mágico de una bodega.

Cerrando este volumen, tenemos una investigación sobre el ordenamiento y clasificación electrónica de información referida a obras literarias y la crítica que las mismas generan. Roberto Pareja, experto en humanidades digitales, desarrolla un minucioso análisis de datos extraídos de varias bases de datos para intentar contestar la siguiente pregunta: ¿Hasta qué punto y en qué contextos, términos que emergen de la crítica literaria ganan fuerza e influencia fuera de la academia? Pareja estudia la forma en que la mediación editorial ha contribuido a construir una imagen de Saenz y su obra que ha generado ejes sobre los que se apoyan la crítica local y global. Este análisis ilumina las relaciones que textualmente se establecen entre la figura de Saenz y otros escritores y poetas bolivianos, resaltando la frecuencia de la aparición de la obra literaria dentro de la búsqueda por autor y por diversas categorías temáticas en las cuales se inscriben sus trabajos literarios y los críticos referidos a su obra. Pareja señala que esto puede ayudar a entender la obra como 
resultado del cruce entre quién escribe, ya sea la obra o la lectura crítica de la misma, y cómo se mueve en circuitos editoriales locales o internacionales. Esto le permite, asimismo, encontrar un fuerte contraste entre la recepción local de la obra saenceana y la internacional/globalizada, y las huellas dejadas en las redes digitales que orquestan y reproducen este tipo de lecturas.

Para finalizar esta introducción nos gustaría señalar que las voces críticas reunidas en este volumen nos recuerdan la voz poética de Saenz:

Yo te digo: te esperaré a través de todos los tiempos. Siempre estaré aquí o allá, estaré siempre tanto en ti como en las cosas

y tú lo sabrás cuando te rodees de la melancolía por el tacto (Muerte por el tacto 113)

A través de los tiempos, Saenz sigue viviendo en la conciencia colectiva de Ixs contribuidores del volumen y esperamos en la de Ixs lectores también.

Queremos finalmente expresar nuestro agradecimiento a Elizabeth Monasterios, a Martha Mantilla y a la Universidad de Pittsburgh, por ofrecernos la oportunidad de componer esta edición especial para la Revista de Estudios bolivianos/Bolivian Studies Journal, donde hemos conseguido reunir un abanico de entradas críticas que - creemos - celebran una obra, la de Jaime Saenz, mostrándonos que la misma tiene todavía mucho que decir. Agradecemos, además, a todos nuestros contribuidores por el interés y el esfuerzo puesto en la realización de este proyecto colectivo. En el proceso de edición aprendimos mucho de todos y cada uno, y nos hicieron ver nuevas avenidas críticas para abordar la obra de Saenz. Un reconocimiento particular va para Javier Molina por generosamente compartir sus memorias con nosotras, así como fotografías de su colección privada. Otro reconocimiento especial a Leonardo García Pabón, amigo de Jaime Saenz y uno de los críticos más importantes de la obra de este escritor, quien nos honró aceptando nuestra invitación a escribir el Postscriptum del volumen. Y uno final a la familia Saenz por habernos permitido la inclusión de fotografías del poeta boliviano y una carta de su autoría.

N.B. Una aclaración ortográfica necesaria respecto al apellido del autor. Muchos artículos críticos encontrados en diferentes bases de datos ponen tilde en la $a$ de Saenz (Sáenz), pero él deletreó su nombre sin tilde. Por esta razón, decidimos excluir la tilde en todas las instancias, aun si se extrae la cita de un crítico que la utilizó. 
(cc) $\mathrm{EY}$

ULS D-Serle $\begin{aligned} & \text { This journal is published by the University Library System of the } \\ & \text { University of Pittsburgh as part of its D-Scribe Digital Publishing }\end{aligned}$ Program, and is cosponsored by the University of Pittsburgh Press. 